\title{
Analysis on the Customer Segmentation of HuaWei Company
}

\author{
Yang Yueyuan
}

\author{
Shanghai University, SLIC, Shanghai, China, 210800 \\ ${ }^{*}$ Corresponding author. Email: 857786088@qq.com
}

\begin{abstract}
With the gradual improvement of the convenience of information acquisition, people can get the information they expected to look for more easily than before. It will bring a lot of convenience for the company to do big data investigation. But at the same time, it may also bring some bad conditions for the company, which need to be avoided, such as over-segmentation when the company is designing their marketing strategy. An over-segmentation could bring a number of drawbacks to the company. For example, the manager of the company may not be able to make inform decisions because over-segmentation could lead the information gathered not accurate or useful at all for the reason that it groups customers into too many parts. Huawei could be regarded as a successful company in recent years due to its outstanding innovation of their smart phone devices. However, it could be quite hard to stand out because people right now are situated in a competitive mobile phone market. Based on this fact, it could lead to people's interest to find out how this company accomplishes their successful marketing strategy and how their customer segmentation is. In other words, this article mainly evaluated Huawei company's performance, especially in terms of its marketing strategy of customer segmentation and it also analyzes whether they have made the common mistake that could be easily made when people are doing their segmentation strategy.
\end{abstract}

Keywords: Huawei company, marketing strategy, customer segmentation

\section{INTRODUCTION}

Huawei company pays their attention to provide information and communication technology infrastructure and smart devices to the people all over the world[1]. According to its marketing strategies, Huawei company's analysis of customer segmentation has been undertaken by using next generation technologies, such as Wi-Fi and big data analytics[2]. With the help of effective customer segmentation, not only their business revenue could witness a rise, but also the awareness of brand could be increased at the same time.

Customer segmentation means dividing all your customers into different groups of people who may share common desires or other traits, such as, gender or level of income[6]. With the existence of a customer segmentation, a company could be able to keep and reach their customers more effectively, because it is a company's duty to satisfy what their customer wants. By grouping their customers, the company could be able to understand their customers' different needs based on different groups, and this could lead the company to offer a better service[7]. However, there is a common mistake called over-segmentation. It usually occurs when a company is doing their customer segmentation, which means that a company divides their customers into too many groups[6], causing a rise of the production cost, cognitive cost and service cost at the same time. What's worse, a company could also lose customers due to over-segmentation because this could provide distractions and information with lower clarity to a manager, which could finally cause the manager be not able to make informed decisions.

This article mainly analyzes Huawei's customer segmentation based on three perspectives: segment attractiveness, competitive advantage and segment compatibility. Also, it contains whether Huawei has made the common mistake when they are designing their customer segmentation. 


\section{HUAWEI COMPANY}

\subsection{Basic Information of Huawei Company}

Huawei company is founded in 1987 and expects to offer digital to individuals in order to construct a fully connected and intelligent society with the help of four key domains - telecom networks, IT, smart devices, and cloud services [3]. In order to achieve this, they will promote universal connectivity and equal access to the Internet[3]. Also, it is their responsibility to penetrate computing and artificial intelligence to every corner of the world, and at the same time to provide superior computing power[3]. Building digital platforms could also be vital because this will help all industries and organizations to become more agile, efficient, and dynamic, which could be quite beneficial to a company[1].

Using AI to redefine the user experience could be a part as well, so that it will be more personal in life. Also, they ranked 49th in the Fortune Global 500 in 2020, while they ranked 68th in the Best Global Brands in 2018 [3]. The milestones that they have made in these years could contain that they have partnerships with more than 700 cities and over 200 companies, that are all form Fortune Global 500, concerning about digital transformation and simultaneously. This company has more than three million users and developers to use their HUAWEI CLOUD to develop products and solutions in 2019, however, the number of this could be much lower during the previous years [1]. As a result, it could be able to find the dramatic growth of Huawei. Additionally, people should be aware that the rapid development of performance is inseparable from the close cooperation of business partners, market segment customer development and service[4].

\subsection{An overview of the Market Segmentation of Huawei Company}

The initial question that may be needed for every company to ask themselves when they start doing their market segmentation should be "Who are your customers?". For Huawei company, its answers rely mainly on the data they get from various studies, and then develop a specific customer segmentation based on these data, as well as a series of marketing schemes aiming at the results of customer segmentation. To be more precise, Huawei company mostly uses next-generation technologies, including $\mathrm{Wi}-\mathrm{Fi}$ and cloud platforms, to find different traits of their customers, for example, what is their interest and what is their job, as well as their spending habits could also be useful for the company to be aware of [3].

What Huawei desires to get from market segmentation could possibly be to understand their customers' shopping motivations more accurately, so that they could align their marketing campaigns more accordingly[3]. To be more precise, after the company gathering all the results from the analysis, they could execute certain targeted marketing campaigns, and allocate marketing resources more accurately in the meantime. Also, they may be able to improve their customer service and retain loyal customers through their customer segmentation [3]. Perhaps more significantly, they could identify potential gaps in the market because of their valid information gathered by the technologies, therefore, gaining an advantage over competitors, and then their revenue and brand awareness will witness an increase as a result[1].

\section{CUSTOMER SEGMENTATION}

\subsection{The Meaning and Importance of Customer Segmentation}

It is vital for a business to figure out what their customers really want because you may have a better chance to convince them to purchase if you just provide exactly what they need. Different people desire various things, and the meaning of customer segmentation's existence is to bring a group of people, who have specific common interests or needs, together because it may not be effective to provide the same provide or service to all of your customers [7] .

For example, some people may not be price sensitive, however, their could be a number of people who care the price of a product very much, then the company is expected to differentiate these two kinds of customers due to their different needs. Also, it is possible that with the help of right segmentation, the firm could be able to identify the most profitable clients and the ones who spend the least money at the same time, and this could be quite significant for the company to get to know because with this information. They could allocate their marketing budget more adequately in the desire of getting a rise in the sales to the key customers[8]. Also, according to a 2017 Malichimp survey, it concludes that the average open rate for segmented campaigns was $14 \%$ higher than for non-segmented campaigns, from this, its importance can also be shown[9].

\subsection{A Common Mistake in Customer Segmentation--Over-Segmentation}

\subsubsection{Cause of occurrence of Over-segmentation}

Customer segmentation allows marketers to have similar needs and information filter groupings, which means that marketers are expected to pay more focus on looking for commonalities in your customers' needs, instead of just finding differences among them, but if 
doing so, over-segmentation could possibly appear. It is easy to understand that carrots are beneficial to people's health, however, a large number of carrots might give adverse effects, the same goes for customer segmentation [8].

\subsubsection{Poor results caused by over-segmentation}

Too much segmentation, apart from requiring people to spend a large amount of time and utilize lots of resources, it can actually hurt your results. To be more detailed, critical mass is required for testing and optimization of activities, if dividing activities into smaller segments, it won't be able to gather enough data to infer trends and thus make right decisions[9]. To be more detailed, if relying on a small sample size to make customization decisions, people may over-customize the information that you have gathered, which actually reduces clarity and leads to distraction[10].

As a result, there might be a dramatic drop of the number of clients because of the improper marketing strategy, which is made based on excessive market segmentation, not to mention the bad effects that may finally bring to the revenue and brand awareness. After all, people's mission to use market segmentation is to lower costs and leads to a higher conversion of campaign [10], as a consequence, people should avoid grouping their customers too much. In other words, over-segmentation may eventually cause irreparable harm to the company. In this way, the meaning and significance of market segmentation will disappear.

\section{EVALUATION OF HUAWEI'S MARKET SEGMENTATION}

\subsection{Segment Attractiveness}

If a segment offers long-term revenue potential in the aspects of growth, buying power, loyalty and so on, as well as the segment is considered to be cost-effective to reach, then it could be seen as a segment with a number of attractiveness. In order to reach this, what people need to do initially is to find a way to evaluate their segment attractiveness. To better assess the attractiveness of each segment of customers, a company is expected to use five criteria to find our which parts of the customers are most feasible and worthy of their company's pursuit, in other words, there could be a question for each manager to ask themselves when they are evaluating segment attractiveness based on the information provided in their own customer analysis "Is this segment identifiable, reachable, substantial, responsive and profitable?'[9].

Huawei company pays attention on the consumer market of college students. To be more detailed, the number of college students could be large, which means there might be a great deal of people who get higher level of education, and they are relatively concentrated in medium-sized cities in the meantime[5]. Generally speaking, a high level of education will lead to a relatively high level of consumption in the future. Not to mention the possible fact that the current college students might be the majority of the grassroots with high incomes in the society once they enter the society for work[5].

According to Huawei's customer analysis based on consumer behavior, it is easy to find that Huawei has a clear idea of who its products are designed for to better meet customers' needs, and segment of Huawei company could be identifiable[10]. Also, college students are easy to have access to, and persuasive communications or product distributions could be effective to them very much because for those young generations, not only they can receive marketing messages quickly using the latest technologies, but they can fully understand them and find a way to purchase the products[4].

As a result, their segment could be reachable. In addition to the question whether the segment is responsible, substantial and profitable, from Huawei's annual report, which contains the sales of its products, it is quite is to find the answer. It could be considered that both college students and people at different ages respond positively. At the same time, the buying power of their customers could be significant because the specific data of Huawei's operating performance in the first half of 2020 is: sales revenue of 454 billion yuan, up 13.1 percent year on year, and net profit margin of 9.2 percent. Of this, consumer revenue was 255.8 billion yuan [1].

\subsection{Competitive Advantage}

If a company is able to serve the segment better than its competitors, then it can be regarded as the segmentation strategy gains competitive advantage. With Huawei's success in these years, it could be regarded that it has succeeded in the industry. There are many reasons for Huawei to be outstanding in such a competitive technology world [5]. Huawei's biggest competitive advantage may lie in its continuous innovation, it has always been committed to providing customers with unique products, so that customers can have the opportunity to constantly upgrade their mobile phones.

In markets like China, and even around the world, Huawei can be credited with providing innovations in cameras and software features that no other competitor has [4]. Additionally, the demand of smart phone market could be large not only in China, thus, Huawei has created different products for different populations, for instance, they have specially designed a series for 
women that is called nova, and for business people they have a series of mate. As a homegrown Chinese phone company, Huawei can compete with the high-end market of international smart phones, such as Sumsung and Apple[6]. Because they followed all these innovative strategies, they were able to achieve success and enter many new markets in a relatively short period of time. It is obvious why they can stand out from the competition in the market.

\subsection{Segment Compatibility}

What could be the most significant point for a company, it may be the company's core competitiveness, brand image and goals, as a result, if the company's market segmentation matches these, then the company also gets compatibility of their market segmentation. From the company analysis, it could be known that Huawei has strong technology research and development ability, as well as a strong sales team, however, the phone is noting like the communication system, which is as long as there is a high technology content, good running stability, the needs of customers can be able to meet[6]. Also, the promotion and sales of communication system and value-added services are mostly focus on key customers not any random one in the market[6]. In the contrast, the sale of mobile phones is faced with numerous and various consumers[6].

As a consequence, under this kind of situation, Huawei did an evaluation of the market. According to the fact that the high-end market has been controlled by manufacturers from the United States and South Korea, proving this market is relatively difficult to break into, and the company's own characteristics, Huawei chose to stick to the middle market. Although there are many brands in the middle market, it does not have a prominent advantage[1]. Therefore, Huawei believes that it should strive for the high-end market and at the same time defend the mid-low market. At the same time, Huawei has developed its own high-end processor chips, Hongmeng operating system, Ark compiler, and $5 \mathrm{G}$ patents and solutions, these could be the reasons why many consumers deeply adore and choose Huawei.

\section{ANALYSIS OF WHETHER HUAWEI HAS DONE AN OVER-SEGMENTATION}

Huawei company perfectly avoids the usual mistake that could have made when a company is constructing their marketing strategy --- over-segmentation because of their various of models of phones, which could covers people from nearly all ages and all levels of consumption. To be more precise, as it has mentioned before, Huawei Company offers different series of their phones, that are Mate, P, Honor and each of them has their targeted customers. Take Mate as an example, phones from Mate series are expected to be sold to business people with middle age. They have certain consumption power and therefore a relative high consumption level, as a result, the price of this series of mobile phones is relatively the higher than the other series as these phone are provided for people who gain consumption power.

From this strategy of Huawei, it can be considered that Huawei is quite clear of who are their customers, and what kind of products are they mainly focus on manufacturing, and also, perhaps the most significant point for a manufacturer to be aware of, what are their products designed and produced for. After getting to known these, the company could successfully avoid over-segmentation as they could be able to differ the customers in the markets, and group them into several but not many various groups, and then design different products towards each of the group to meet their needs, so as to make a profit through their effective customer segmentation strategy.

\section{CONCLUSION}

In general, Huawei is a company that emphasizes innovation, but also likes analysis. At the completion of customer segmentation, they chose the college students as their main target customers, because they believe most college students will become a part of people with mid-level income in the future. College students could be able to keep up with the trend of The Times. The marketing strategy can also be achieved quickly. At the same time, for other groups, they also launched different series of products to meet the needs of other groups. For example, they launched Products of Nova series for women. Huawei company has also done to the whole mobile phone market analysis, proposed the most important point is that now the high-end smart phones in the international market has been majorly taken by the companies from the United States and South Korea, therefore, the company make a informed decision that is to mainly keep the mid-market. In terms of the question of whether they have made the over-segmentation mistake, the answer should be no because Huawei divided their clients into the college students, women, business people, for every group of people they have a set of special products, but these products are not very different from each other, there is commonness among them, which means that if young generations desire to purchase the products designed for business people is also possible.

\section{ACKNOWLEDGMENT}

Here is my great appreciate for the teachers who offer me kind a huge amount of help when there is trouble during this essay writing. Also, this paper is inseparable from the teacher's guidance from topic selection to completion. In the process of writing, constant communication between the teacher and me 
made my thoughts and also, contents of what I am going to focus clearer, and provided me with practical guidance as well. At the same time, the teacher modified my paper carefully and comprehensively, so that I could finish the writing smoothly.

\section{REFERENCES}

[1] Huawei Technologies Co., Ltd , Our Company, https://www.huawei.com/en/corporate-information, 2020.

[2] Huawei Technologies Co.,Ltd Customer Segment Analysis, 2020.

https://e.huawei.com/en/solutions/industries/ retail/digital-store/customer-segment-analysis.

[3] Huawei Technologies Co.,Ltd Leading Connectivity \&Intelligence, 2020.

https://e.huawei.com/en/about/huawei enterprise.

[4] Weiyi Xia, The Marketing strategy of HUAWEI Smart phone in China [J].ICMSIT 2017: $4^{\text {th }}$ International Conference on Management Science, Innovation, and Technology 2017 Faculty of Management Science, Suan Sunandha Rajabhat University, page 144-155.

[5] Romans Dmitrijevs, Research on Marketing Strategy of Huawei Mobile Phone in European Market [J].Open Journal of Business and Management .

Vol.8No.3.https://www.scirp.org/journal/paperinfo rmation.aspx?paperid $=10012$

[6] Turnbull, Peter W., Leek Sheena \& Ying Grace, Customer Confusion: The Mobile Phone Market $[\mathrm{J}]$. Journal of Marketing Management, 16(1):143-163

[7] Mark Camilleri, Market Segmentation, Targeting and Positioning [M].Travel Marketing, Tourism Economics and the Airline Product: An Introduction to Theory and Practice Edition: 1 Chapter: 4.

[8] YORAM (JERRY) WIND and DAVID R. BELL, Market Segmentation[M]. Ch11-H8566.qxd, 2012, page 222-244

https://faculty.wharton.upenn.edu/wp-content/uplo ads/2012/04/0702_Market_Segmentation.pdf

[9] Trama Scott (2018), Customer Segmentation: Methods, Techniques, and Real Examples. https://technologyadvice.com/blog/marketing/cust omer-segmentation-methods/.

[10] Wilhelmus Hary Susilo, An Impact of Behavioral Segmentation to Increase Consumer Loyalty: Empirical Study in Higher Education of Postgraduate Institutions at Jakarta [J],
Procedia-Social and Behavior Sciences 229 (2016) 183-195. 